\title{
Study of Post Phototherapy Serum Bilirubin Rebound Levels in Near Term and Term Neonates
}

\author{
Singh $\mathrm{H}^{1}$, Devpura $\mathrm{K}^{2}$, Gothwal $\mathrm{S}^{3}$, Nangliya V. L. ${ }^{4^{*}}$, Mathur $\mathrm{P}^{5}$, Agarwal $\mathrm{A}^{6}$
}

${ }^{1}$ Resident, Department of Pediatrics, Sawai Man Singh Medical College, Jaipur, Rajasthan, India

${ }^{2}$ Senior Professor, Department of Pediatrics, Sawai Man Singh Medical College, Jaipur, Rajasthan, India

${ }^{3,5}$ Assistant Professor, Department of Pediatrics, Sawai Man Singh Medical College, Jaipur, Rajasthan, India

${ }^{4}$ Assistant Professor, Department of Biochemistry, Sawai Man Singh Medical College, Jaipur, Rajasthan, India

${ }^{6}$ Intern, Department of Pediatrics, Sawai Man Singh Medical College, Jaipur, Rajasthan, India

*Corresponding author: Dr. Nangliya V. L.

Abstract

Neonatal hyperbilirubinemia is common in first week of life. Nearly $60 \%$ term \& $80 \%$ preterm neonates develop jaundice in first week of life. American Academy of Pediatrics recommends that new born discharged within 48 hours should have a follow-up visit after 48 - 72 hours for any significant neonatal jaundice. These babies may develop jaundice which may be over looked or delay in recognition unless closely monitored. So it is necessary to measure serum total bilirubin in all jaundiced infants and ensure follow-up evaluation within 2 days of all infants discharged prior to 48 hours. Concern regarding early discharge is bilirubin induced neurological dysfunction (BIND) in healthy term infants even without hemolysis. No upper limit of serum bilirubin levels are defined for development of BIND in icteric new born but serum bilirubin level $>20 \mathrm{mg} / \mathrm{dl}$ is likely to be toxic and leads to significant brain damage. The pathogenesis of BIND is complex and related to the interplay between levels of unconjugated bilirubin, gestational maturity of infants and integrity of blood brain barrier. The concept of prediction of neonatal jaundice is an attractive option for clinical assessment of neonatal jaundice. Our study states that out of 150 neonates, 86 neonates $(57.3 \%)$ no rebound hyperbilirubinemia seen, $47(31.3 \%)$ developed insignificant rebound hyperbilirubinemia (i.e. serum bilirubin level increases after discontinuation of phototherapy but not crossed cut-off value of starting phototherapy), $10(6.7 \%)$ developed significant bilirubin rebound (SBR) at 12 hours of discontinuation of phototherapy and 7 (4.7\%) developed SBR at 24 hours of discontinuation of phototherapy. So patient having higher serum bilirubin at the time of discontinuation of phototherapy along with risk factors developed more SBR. There are only few options for treatment of neonatal jaundice which are: Phototherapy, Exchange transfusion, Drugs like phenobarbitone, intravenous immunoglobulin.

Keywords: Neonatal Hyperbilirubinemia, Neonatal Jaundice, Rebound Hyperbilirubinemia, Phototherapy.

Copyright @ 2020: This is an open-access article distributed under the terms of the Creative Commons Attribution license which permits unrestricted use, distribution, and reproduction in any medium for non-commercial use (NonCommercial, or CC-BY-NC) provided the original author and source are credited.

\section{INTRODUCTION}

Neonatal hyperbilirubinemia is common in first week of life. Nearly $60 \%$ of term and $80 \%$ of preterm [1] neonates develop jaundice in first week of life. High serum bilirubin level may be toxic to the developing brain and cause neurological impairment [1]. American Academy of Pediatrics recommends that new born who discharged within 48 hours should have a follow-up visit after 48 to 72 hours for any significant neonatal jaundice [2]. These babies may develop jaundice which may be over looked or delay in recognition unless the baby is closely monitored. So it is necessary to measure serum total bilirubin (STB) in all jaundiced infants and ensure follow-up evaluation within 2 days of all infants discharged prior to 48 hours. Concern of Pediatrician regarding early discharge is related to bilirubin induced neurological dysfunction (BIND) in healthy term infants even without hemolysis. No exact higher serum bilirubin level are defined for development of BIND in icteric new born but serum bilirubin level more than $20 \mathrm{mg} / \mathrm{dl}$ is likely to be toxic and may lead to significant damage to the brain [3]. The exact pathogenesis of BIND is complex and is believed to be related to the interplay between levels of unconjugated bilirubin, gestational maturity of infants and integrity of blood brain barrier [1,4]. The concept of prediction of neonatal jaundice is an attractive option for clinical assessment of neonatal jaundice. This visual assessment of STB levels as suggested by Kramer [4], which relies on the cephalo-caudal progression of jaundice with a rising serum bilirubin level (head and neck - 4 to $8 \mathrm{mg} / \mathrm{dl}$; upper trunk - 5 to $12 \mathrm{mg} / \mathrm{dl}$; lower 
trunk and thigh -8 to $16 \mathrm{mg} / \mathrm{dl}$; palm and sole - > 15 $\mathrm{mg} / \mathrm{dl})$. In most cases, neonatal jaundice is benign and no intervention is required. But around $5-10 \%$ of them have clinically significant jaundice which needs treatment [2]. There are only few options for treatment of neonatal jaundice which are: (1) Phototherapy; (2) Exchange transfusion; (3) Drugs like phenobarbitone; (4) IVIG (intravenous immunoglobulin). Treatment of neonatal jaundice by exchange transfusion is costly, relatively invasive, time consuming and associated with complications. Early treatment with phototherapy is simple, effective, cheap and have relatively lesser side effects. Phototherapy is available in following modes; single surface phototherapy, double surface phototherapy, high intensity phototherapy, halogen phototherapy, fibre optic blanket, CFL phototherapy and LED phototherapy. Discontinuation of phototherapy too early may lead to rise of serum bilirubin to an unacceptable level, which may require further reinstitution of phototherapy [3]. Phototherapy is stopped when the serum bilirubin level is below the phototherapy cut off value as per American academy of pediatrics guidelines [3]. The need for measurement of serum bilirubin after stopping phototherapy to see rebound has remained a topic of interest by researchers recently. There are only limited studies available in our country and this type of study was not done in our centre previously. So this study was designed to determine the patterns and magnitude of post phototherapy rebound serum bilirubin in neonates requiring phototherapy for hyperbilirubinemia. Significant Bilirubin rebound (SBR) is defined as postphototherapy bilirubin level needing reinstitution of phototherapy [5].

\section{AIM AND OBJECTIVE}

\section{Aim}

To assess the serum bilirubin rebound following discontinuation of phototherapy in near term and term neonates.

\section{Objective}

To assess the risk factors and the pattern of rebound serum bilirubin at $12 \mathrm{hrs}$ and $24 \mathrm{hrs}$ post phototherapy.

\section{METHODS}

This study is a hospital based prospective observational study, conducted during September 2017 to December 2018 in Department of Paediatric Medicine, SMS Medical College and attached group of hospitals, Jaipur. Sample size was calculated at $95 \%$ confidence level, alpha error of 0.05 assuming $11.3 \%$ rebound in total Serum Bilirubin measured after 24 hours of discontinuation of phototherapy in neonate $\geq$ 35 weeks of gestational age admitted for hyperbilirubinemia in neonatal ward as per the reference article [6]. At 5\% of absolute allowable error in the rebound of total serum bilirubin the required sample size was 150 neonates.
Inclusion criteria includes near term $(35-36$ 6/7 week) [1] and term (37- 42 week) [1] neonates with hyperbilirubinemia receiving phototherapy for first time. (as per AAP guideline).

Exclusion criteria includes neonates with gestational age $<35$ weeks and $>42$ weeks, ccritically sick babies requiring mechanical ventilation, babies undergone for exchange transfusion or received IVIG, direct hyperbilirubinemia, negative consent for the study.

Methodology includes neonates (Between 3542 weeks) with hyperbilirubinemia and requiring phototherapy according to the AAP guidelines were enrolled in the study. Written Informed Consent, detailed history regarding the onset, symptoms and risk factor for neonatal jaundice were obtained. General physical examination was done. Gestational age was assessed by Modified bellard score. Baseline Total S. Bilirubin, Direct Bilirubin, Indirect Bilirubin, along with Maternal blood group (MBG), Baby blood group (BBG), Direct coomb test (DCT), Glucose-6-phosphate dehydrogenase (G6PD) deficiency, Thyroid profile, Complete blood count (CBC), Peripheral blood film (PBF) detail with Reticulocyte count, Blood culture and sensitivity, were obtained. Walter \& Gerarde method (Diazo) was used for determination of serum bilirubin level.

Serum bilirubin was measured 12 hourly. Serum bilirubin estimation was done by Micro lab automatic analyser based on the Walter \& Gerarde method (Diazo) using venous blood sample. Blood Group of baby and mother with blood group A \& B was determined with anti $\mathrm{A}$ and anti B serum by indirect slide method. Rhesus grouping of baby and mother was determined by slide method using anti D serum. Complete blood counts were done by auto analyser. For blood culture and sensitivity test, the site of venipuncture was cleaned with an alcohol wipe and left to dry for a minute. Povidone iodine is applied in concentric circle outward; allow drying for at least 60 seconds. $2 \mathrm{ml}$ of blood is obtained in blood culture bottle and transported to laboratory for culture and sensitivity test. Infants under light emitting diode (LED) phototherapy (Neonest LED phototherapy) were kept naked except for eyes and genitalia. Neonate was taken out only for feeding. LED phototherapy with at least 8$10 \mathrm{microwatt} / \mathrm{cm}^{2} / \mathrm{nm}$ spectral irradiance at infants level (as measured with flux meter), $430-490 \mathrm{~nm}$, at $20 \mathrm{~cm}$ distance from baby was used.

Phototherapy was stopped when one value of serum bilirubin level reached below cut-off line according to the following chart.

Serum bilirubin levels were measured at 12 hours and 24 hours after discontinuation of phototherapy to see rebound hyperbilirubinemia. Serum 
bilirubin level requiring reinstitution of Phototherapy as per the AAP bilirubin chart were considered as Significant Bilirubin Rebound (SBR) [7].

Data collecting sheet was checked for completeness and stored securely. Data from the collecting sheet was entered into a computer using Microsoft Excel 2012 package. It was then exported into statistical program SPSS version 17 software package for analysis with the help of a statistician. Continuous variables (age at onset of jaundice, sex, gestational age, birth weight, duration of phototherapy, risk factors etc.) were summarized. A table of baseline characteristics was generated. Appropriate test were applied. P-value of less than 0.05 was considered to be statistically significant.

\section{RESULTS}

Table-1: Observations of Study

\begin{tabular}{|l|l|l|l|}
\hline S. No & Characteristics & Data & SBR \\
\hline 1 & Total neonates & 150 & 17 \\
\hline 2 & Gestation & & \\
& \multicolumn{1}{|c|}{ Near term } & $83(55.5 \%)$ & $12(14.5 \%)$ \\
& \multicolumn{1}{|c|}{ Male } & $87(44.7 \%)$ & $5(7.5 \%)$ \\
\hline 3 & Gender & $87(58 \%)$ & $10(11.5 \%)$ \\
& \multicolumn{1}{|c|}{$63(42 \%)$} & $7(11.1 \%)$ \\
\hline 4 & Sex ratio & $1.38: 1$ & \\
\hline 5 & Birth weight - Range & $2000 \mathrm{~g}-4200 \mathrm{~g}$ & \\
\hline 6 & Bilirubin Rebound- & $10(6.7 \%)$ & \\
& Significant (SBR)- At 12 hours & $7(4.7 \%)$ & \\
& At 24 hours & $17(11.3 \%)$ & \\
& Total & $47(31.3 \%)$ & \\
& Insignificant bilirubin rebound & $86(57.3 \%)$ & \\
& No rebound & P- value & \\
\hline 7 & Significant etiology & 0.004 & \\
& Sepsis & 0.001 & \\
& G6pd deficiency & 0.006 & \\
& Rh incompatibility & 0.005 & \\
& DCT positive & \multicolumn{2}{|l}{} \\
\hline
\end{tabular}

Table-2: Distribution of study subjects according to gender, gestational age and birth weight

\begin{tabular}{|c|c|c|c|c|}
\hline \multirow{2}{*}{\multicolumn{2}{|c|}{ Variables }} & \multirow[t]{2}{*}{ Total no of Cases } & \multicolumn{2}{|c|}{ Rebound Hyperbilirubinemia } \\
\hline & & & No / Insignificant & Significant \\
\hline \multirow[t]{2}{*}{ Sex } & Male & $87(58 \%)$ & $77(88.5 \%)$ & $10(11.5 \%)$ \\
\hline & Female & $63(42 \%)$ & $56(88.9 \%)$ & $7(11.7 \%)$ \\
\hline \multirow[t]{2}{*}{$\begin{array}{l}\text { Gestational Age } \\
\text { (weeks) }\end{array}$} & $\begin{array}{l}\text { Near Term } \\
(35-366 / 7 \text { weeks })\end{array}$ & $83(55.3 \%)$ & $71(85.5 \%)$ & $12(14.5 \%)$ \\
\hline & $\begin{array}{l}\text { Term } \\
(37-42 \text { weeks })\end{array}$ & $67(44.7 \%)$ & $62(92.5 \%)$ & $5(7.5 \%)$ \\
\hline \multirow{5}{*}{$\begin{array}{l}\text { Birth Weight } \\
\text { (kg) }\end{array}$} & $2.0-2.49$ & $55(36.7 \%)$ & $50(90.9 \%)$ & $5(9.1 \%)$ \\
\hline & $2.5-2.99$ & $63(42 \%)$ & $54(85.7 \%)$ & $9(14.3 \%)$ \\
\hline & $3.0-3.49$ & $26(17.3 \%)$ & $24(92.3 \%)$ & $2(7.7 \%)$ \\
\hline & $3.5-3.99$ & $5(3.3 \%)$ & $4(80 \%)$ & $1(20 \%)$ \\
\hline & $\geq 4.0$ & $1(0.6 \%)$ & $1(100 \%)$ & $0(0.0 \%)$ \\
\hline
\end{tabular}

Table-2 shows that there were total 150 neonates; out of them 83 neonates $(55.3 \%)$ were near term, 67 neonates $(44.7 \%)$ were term, 87 neonates $(58 \%)$ were male, 63 neonates $(42 \%)$ were female, 55 neonates $(36.7 \%)$ had birth weight $2.0-2.499 \mathrm{~kg}, 63$ neonates $(42 \%)$ had $2.500-2.999 \mathrm{~kg}, 26$ neonates $(17.3)$ had $3.0-3.499 \mathrm{~kg}, 5$ neonates $(3.3 \%)$ had $3.500-3.999$ $\mathrm{kg}, 1$ neonate $(0.6 \%)$ had $\geq 4.0 \mathrm{~kg}$. Birth weight ranged from $2000 \mathrm{~g}$ to $4200 \mathrm{~g}$.

Table-3: Rebound hyperbilirubinemia among study subjects

\begin{tabular}{|l|l|l|}
\hline Rebound hyperbilirubinemia & N & Percentage \\
\hline No rebound & 86 & 57.3 \\
\hline Insignificant rebound & 47 & 31.3 \\
\hline Significant rebound at 12 hours & 10 & 6.7 \\
\hline Significant rebound at 24 hours & 7 & 4.7 \\
\hline Total Significant rebound & 17 & 11.3 \\
\hline Total & 150 & 100.0 \\
\hline
\end{tabular}


This table illustrates the percentage of significant rebound hyperbilirubinemia was $11.3 \%$. Out of 150 neonates, in 86 neonates $(57.3 \%)$ no rebound, 47 neonates $(31.3 \%)$ developed insignificant rebound, 10 neonates $(6.7 \%)$ developed significant rebound at 12 hours of discontinuation of phototherapy, and 7 neonates $(4.7 \%)$ developed significant rebound at 24 hours of discontinuation of phototherapy.

Table-4: Rebound hyperbilirubinemia in relation to etiological diagnosis

\begin{tabular}{|l|l|l|l|l|l|l|}
\hline \multirow{2}{*}{$\begin{array}{l}\text { Etiological } \\
\text { Diagnosis }\end{array}$} & Total & \multicolumn{4}{|l|}{ Rebound hyperbilirubinemia } & \multirow{2}{*}{ P value } \\
\cline { 2 - 6 } & & \multicolumn{2}{|l|}{ Absent } & \multicolumn{2}{|l|}{ Significant } & \\
\cline { 2 - 6 } & & $\mathbf{N}$ & $\mathbf{\%}$ & $\mathbf{N}$ & $\mathbf{\%}$ & \\
\hline Cephalhematoma & 11 & 9 & 81.8 & 2 & 18.2 & 0.802 \\
\hline Asphyxia & 20 & 17 & 85 & 3 & 15 & 0.859 \\
\hline Sepsis & 22 & 15 & 68.2 & 7 & 31.8 & 0.004 \\
\hline G6PD deficiency & 4 & 1 & 25 & 3 & 75 & 0.001 \\
\hline ABO incompatibility & 35 & 28 & 80 & 7 & 20 & 0.113 \\
\hline Rh incompatibility & 11 & 7 & 63.6 & 4 & 36.4 & 0.026 \\
\hline DCT positive & 5 & 2 & 40 & 3 & 60 & 0.005 \\
\hline Hypothyroidism & 5 & 5 & 100 & 0 & 0 & 0.923 \\
\hline
\end{tabular}

Table-4 depicts that significant association was seen between rebound hyperbilirubinemia and Sepsis $(\mathrm{p}=0.004), \quad$ G6PD deficiency $\quad(\mathrm{p}=0.001), \quad \mathrm{Rh}$ incompatibility $(\mathrm{P}=0.026)$, DCT positivity $(\mathrm{p}=0.005)$.

Table-5: Rebound hyperbilirubinemia in relation to age at onset of hyperbilirubinemia

\begin{tabular}{|l|l|l|l|l|l|}
\hline \multirow{2}{*}{$\begin{array}{l}\text { Age at onset of } \\
\text { hyperbilirubinemia }\end{array}$} & Total & \multicolumn{3}{|l|}{ Rebound hyperbilirubinemia } \\
\cline { 2 - 6 } & & \multicolumn{2}{|c|}{ No/Insignificant } & \multicolumn{2}{|c|}{ Significant } \\
\cline { 2 - 6 } & & $\mathbf{N}$ & $\mathbf{\%}$ & $\mathbf{N}$ & $\mathbf{\%}$ \\
\hline$\leq 24 \mathrm{hrs}$ & 0 & 0 & 0 & 0 & 0 \\
\hline $25-48 \mathrm{hrs}$ & 29 & 24 & 82.8 & 5 & 17.2 \\
\hline $49-72 \mathrm{hrs}$ & 38 & 32 & 84.2 & 6 & 15.8 \\
\hline $73-96 \mathrm{hrs}$ & 28 & 25 & 89.3 & 3 & 10.7 \\
\hline $97-120 \mathrm{hrs}$ & 18 & 16 & 88.9 & 2 & 11.1 \\
\hline $121-144 \mathrm{hrs}$ & 16 & 15 & 93.7 & 1 & 6.3 \\
\hline$\geq 145 \mathrm{hrs}$ & 21 & 21 & 100 & 0 & 0 \\
\hline Total & 150 & 133 & 88.7 & 17 & 11.3 \\
\hline
\end{tabular}

Chi-square $=4.865$ with 5 degrees of freedom; $\mathrm{P}=0.493$

Table-5 depicts that significant hyperbilrubinemia was seen more in neonates with age at onset of hyperbilrubinemia at $24-48$ hours (17.2\%), followed by 49-72 hours (15.8\%); 97-120 hrs (11.1\%); $73-96$ hrs $(10.7 \%)$. P value was 0.493 .

Table-6: Rebound hyperbilirubinemia in relation to duration of phototherapy

\begin{tabular}{|l|l|l|l|l|l|}
\hline Duration of phototherapy & \multirow{2}{*}{ Total } & \multicolumn{3}{|c|}{ Rebound hyperbilirubinemia } \\
\cline { 3 - 6 } & & \multicolumn{2}{|c|}{ No/Insignificant } & \multicolumn{2}{|c|}{ Significant } \\
\hline & & $\mathbf{N}$ & $\mathbf{\%}$ & $\mathbf{N}$ & $\mathbf{\%}$ \\
\hline$<12 \mathrm{hour}$ & 0 & 0 & 0 & 0 & 0 \\
\hline $12-23 \mathrm{hrs}$ & 23 & 22 & 95.6 & 1 & 4.4 \\
\hline $24-35 \mathrm{hrs}$ & 33 & 30 & 90.9 & 3 & 9.1 \\
\hline $36-47 \mathrm{hrs}$ & 46 & 39 & 84.8 & 7 & 15.2 \\
\hline $48-59 \mathrm{hrs}$ & 22 & 19 & 86.4 & 3 & 13.6 \\
\hline $60-71 \mathrm{hrs}$ & 23 & 20 & 87 & 3 & 13 \\
\hline$\geq 72 \mathrm{hrs}$ & 3 & 3 & 100 & 0 & 0 \\
\hline Total & 150 & 133 & 88.7 & 17 & 11.3 \\
\hline
\end{tabular}

Chi-square $=2.539$ with 5 degrees of freedom; $\mathrm{P}=0.940$

Table- 6 shows that when phototherapy is given for $12-23$ hours, only 1 neonate $(4.4 \%)$ developed SBR. Whereas when phototherapy given for 24-35 hrs 3 neonates $(9.1 \%)$ developed SBR. When phototherapy given 36-47 hours 7 neonates (15.2\%) developed SBR. $13.6 \%$ neonates with duration of phototherpy $48-59 \mathrm{hrs}$ and $13 \%$ neonates with duration of phototherapy 60-71 hrs developed SBR. P value was 0.940 . 
Table-7: Serum bilirubin at 12 hours among study subjects

\begin{tabular}{|l|l|l|l|l|}
\hline Rebound hyperbilirubinemia & $\mathbf{N}$ & Mean & Std. Deviation & P value \\
\hline No/Insignificant & 140 & 12.6 & 2.3 & $<0.001$ \\
\cline { 1 - 4 } Significant & 10 & 16.0 & 1.6 & \\
\hline
\end{tabular}

Table-7 depicts that mean serum bilirubin was higher $(16 \mathrm{mg} / \mathrm{dl})$ in patients with significant rebound hyperbilirubinemia at 12 hours as compared to those with no or insignificant rebound hyperbilirubinemia $(12.6 \mathrm{mg} / \mathrm{dl})$. $\mathrm{P}$ value was 0.001 .

\section{DISCUSSION}

This was a hospital based prospective observational study, conducted during September 2017 to December 2018 in Department of Paediatric Medicine, SMS Medical College, Jaipur and attached group of hospitals.

Our study was focussed on finding out pattern of rebound serum bilirubin after discontinuation of phototherapy and various factors affecting it.

Gestational age and neonatal jaundice; in our study there were 150 neonates with neonatal jaundice, out of them $83(55.3 \%)$ were near term and 67 (44.7\%) were term gestation. Mean gestational age of neonates was $36.96 \pm 1.71$ weeks. Similarly mean gestational age in the study of Chang et al., [8] and Valinjkar et al., [9] was $38+/-1.7$ weeks and $36.5+/-5.1$ weeks respectively.

Gender distribution of neonatal jaundice; in our study, there were 150 neonates; among which 87 neonates $(58 \%)$ were male and 63 neonates $(42 \%)$ were female and the sex ratio was 1.38: 1 , showing male sex predominance. Male predominance may be explained due to higher incidence of sepsis and G6PD deficiency which predispose more male neonates to develop pathological neonatal jaundice in comparison to female neonates. Diamond LK et al ${ }^{[10]}$, proposed a hypothesis for greater susceptibility to infection in male neonates due to factors responsible for defective immunoglobulin synthesis, which is located on " $\mathrm{X}$ " chromosome. These results were comparable with Arakhita Swain et al., [11] and Richa Soni et al., [12] as these studies also show male predominance. Arakhita Swain et al., [11] studied 126 neonates out of them 70 were male and 56 were female with sex ratio 1.25: 1 ; they found that $9 \%$ of female and $12.9 \%$ of male neonates developed SBR. Richa soni et al., [12] found that out of 509 neonates $295(58 \%)$ were male and $214(42 \%)$ were female.

Distribution of neonatal jaundice according to birth weight; in our study, out of 150 neonates 55 $(36.7 \%)$ had birth weight $2.0-2.499 \mathrm{~kg}, 63$ neonates (42\%) had 2.500-2.999 kg, 26 neonates (17.3) had 3.0$3.499 \mathrm{~kg}, 5$ neonates $(3.3 \%)$ had $3.500-3.999 \mathrm{~kg}, 1$ neonate $(0.6 \%)$ had $\geq 4.0 \mathrm{~kg}$. Birth weight ranged from $2000 \mathrm{~g}$ to $4200 \mathrm{~g}$ with median birth weight was $2.5 \mathrm{Kg}$. Mean birth weight was $2.63 \mathrm{Kg} \pm 0.39 \mathrm{Kg}$.
Similarly mean gestational age in the study of Pearl W Chang et al., [8] and Subhash K Valinjkar et al., [9] (2017) was $3.237+/-0.577 \mathrm{~kg}$ and $2.43+/-1.12$ $\mathrm{kg}$ respectively. Median birth weight in the study of Ismail Mohamed Elhawary et al., [13] was 2.9 (1.300 $4.700) \mathrm{kg}$.

Rebound hyperbilirubinemia; in this study there were 150 neonates out of which 17 neonates $(11.3 \%)$ had significant bilirubin rebound, out of which 12 were near term and 5 were term neonates. These results were comparable with Arakhita Swain et al., [11] who studied 126 neonates and found that 14 neonates $(11.1 \%)$ having significant bilirubin rebound. Kaplan et al., [14] also had similar results in which $13.2 \%$ neonates out of 226 neonates had post phototherapy serum bilirubin rebound. These results were comparable with Praveen et al., [15] who found that 23 neonates $(9.2 \%)$ out of 250 neonates had SBR requiring reinstitution of phototherapy. Similarly Dr Subhash K Valinjkar et al., [9] found that out of 300, 33 neonates $(11 \%)$ developed rebound hyperbilirubinemia; basic difference in their study was that they also included preterm neonates $<35$ week in there study. Similarly Nikoo Niknafs et al., [6] found that 13 neonates $(11.3 \%)$ out of 115 neonates developed SBR. Richa Soni et al., [12] found that out of 509, 63 neonates $(12 \%)$ developed SBR.

In contrast to our study Pearl W Chang et al., [8] found only $4.6 \%$ of neonates developed rebound hyperbilirubinemia; and Ismail Mohamed Elhawary et al., [13] found that $24.9 \%$ of studied neonates developed SBR. This wide range of variability in results of SBR in various study may be due to study plan not being uniform with regard to timing of measurement of serum bilirubin rebound, prematurity, birth weight and presence of other risk factors.

Rebound hyperbilirubinemia in relation to gender; out of 150 neonates, total 17 neonates developed rebound; among them 10 were male $(11.5 \%)$ and 7 were female $(11.1 \%)$. No significant difference was found in the percentage of rebound hyperbilirubinemia among male and female subjects. These results were comparable with Arakhita Swain et al., [11] who studied 126 neonates out of them 70 were male and 56 were female with sex ratio 1.25: 1 ; they found that $9 \%$ of female and $12.9 \%$ of male neonates developed SBR. Richa Soni et al., [12] found that out of 509 neonates 295 (58\%) were male and 214 (42\%) were female.

Rebound hyperbilirubinemia in relation to Gestational age; gestational age of 83 neonates $(55.3 \%)$ 
was 35-36 6/7 week (Near term) and 67 neonates $(44.7 \%)$ were $37-42$ week. The mean gestational age of neonates was $36.96 \pm 1.71$ weeks. Rebound hyperbilirubinemia was more in near term neonates $(14.5 \%)$ as compared to term neonates $(7.5 \%)$. This difference was however not found to be statistically significant $(\mathrm{P}=0.278)$. Richa Soni et al., [12] in a similar study found that $20 \%$ of SBR was due to prematurity. Similarly SBR was more in preterm neonates in many other studies like Dr Subhash K Valinjkar et al., [9] (42.4\%); Bansal et al., [5] (22.5\%); Kaplan M et al., [14] $(21.9 \%)$.

Rebound hyperbilirubinemia in relation to birth weight; no significant association was found between rebound hyperbilirubinemia and birth weight of neonates $(\mathrm{p}=0.797)$.

Arakhita Swain et al., [11], Bansal et al., [5], Kaplan M et al., [14] found that birth weight $<2000$ $\mathrm{gm}$. found to be significant risk factor for SBR. And no significant association were found in relation to hyperbilirubinemia and SBR in babies more than 2000 gm. In our study birth weight ranged from $2000 \mathrm{~g}$ to $4200 \mathrm{~g}$.

Rebound hyperbilirubinemia in relation to etiological diagnosis; in our study significant association was seen between rebound hyperbilirubinemia and Sepsis $(\mathrm{p}=0.004)$, G6PD deficiency $(\mathrm{p}=0.001), \mathrm{Rh}$ incompatibility $(\mathrm{P}=0.026)$, DCT $(p=0.005)$. So Rebound hyperbilirubinemia was significantly higher in neonates with hemolytic disease especially G6PD deficiency and sepsis. These results were comparable to the study done by Arakhita swain et al., [11]; Al-Saedi et al., [16].

In our study it was found that SBR was observed mainly in presence of risk factors. Similar observation were made by Al-Saedi et al., [16], Arakhita Swain et al., [11] and Richa soni et al., [12].

Rebound hyperbilirubinemia in relation to age at onset of hyperbilirubinemia; significant hyperbilrubinemia was seen more in neonates with age at onset of hyperbilrubinemia at $24-48$ hours (17.2\%), followed by $49-72$ hours $(15.8 \%)$; 97-120 hours $(11.1 \%) ; 73$ - 96 hours $(10.7 \%)$. No significant association was however found between age at onset of hyperbilrubinemia and rebound hyperbilrubinemia $(\mathrm{p}=0.493)$. Among the neonates with SBR $64.7 \%$, neonates developed neonatal jaundice within $72 \mathrm{hrs}$ of life. Observation made by Arakhita Swain et al., [11] were similar to our study who found that $71.4 \%$ neonates with SBR developed jaundice in initial 3 day of life but no significant association found between age at onset of hyperbilirubinemia and SBR ( $\mathrm{P}$ value$0.3997)$.

In contrast to our study Bansal et al., [5], and Kaplan M et al., [14], found that in there study age of onset of phototherapy $<60$ hours and $<72$ hours of postnatal life is a risk factor for SBR respectively.

Rebound hyperbilirubinemia in relation to duration of phototherapy; when phototherapy was given for 12-23 hours, only 1 neonate $(4.4 \%)$ developed SBR. Whereas when phototherapy was given 24-35 hours 3 neonates $(9.1 \%)$ developed SBR. When phototherapy was given 36-47 hours 7 neonates (15.2\%) developed SBR. $13.6 \%$ neonates with duration of phototherapy 48-59 hours and $13 \%$ neonates with duration of phototherapy 60-71 hours developed SBR. This difference in occurrence of SBR in relation to duration of phototherapy was however not found to be statistically significant $(\mathrm{P}=0.940)$.

There were lot of variability in relation to duration of study and SBR. Some studies shows that short duration of phototherapy had a risk factor for SBR while other shows that longer duration of phototherapy had a risk factor for SBR. While our study shows no significant association between duration of phototherapy and SBR.

Arakhita Swain et al., [11] found that longer duration of phototherapy ( $>72$ hours) required to treat neonates could be an indicator for increased chances of rebound hyperbilirubinemia. In contrast to this study Berkwitt et al., [17], Kaplan M et al., [14], and M Elhawary et al., [13] found that short duration of phototherapy was found to be risk factor for SBR, as phototherapy may be discontinued early while the rise in serum bilirubin level may continue, concomitant with immaturity of bilirubin conjugation process.

Serum bilirubin at 12 hours and 24 hours among study subjects; in our study mean serum bilirubin after discontinuation of phototherapy in patients with significant rebound hyperbilirubinemia was higher $16 \mathrm{mg} / \mathrm{dl}$ and $17.9 \mathrm{mg} / \mathrm{dl}$ at 12 hours and 24 hours respectively as compared to those with no or insignificant rebound hyperbilirubinemia $12.6 \mathrm{mg} / \mathrm{dl} 13$ $\mathrm{mg} / \mathrm{dl}$ at 12 hours and 24 hours respectively and this difference was found to be statistically significant $(p<0.001)$. So patient having higher serum bilirubin at the time of discontinuation of phototherapy along with risk factors developed more SBR. These results were similar to Berkwitt et al., [17], Chang et al., [8] and M Elhawary et al., [13] who found that higher serum bilirubin at discharge or discontinuation of phototherapy relative to phototherapy threshold was considered as a significant risk factor. In contrast, Niknafs et al., [6] found that discontinuation of phototherapy at lower serum bilirubin levels would not prevent bilirubin rebound.

\section{Summary AND CONCLUSiON}

\section{Summary}

- This was a hospital based prospective observational study carried out on near term and term neonates 
admitted in the Department of Pediatrics, SMS Medical College, Jaipur and attached group of hospitals.

- The duration of the study was from September 2017 to December 2018.

- A sample size of 150 neonates was taken. Near term $(35-366 / 7 \text { week })^{1}$ and term $(37-42 \text { week })^{1}$ neonates with hyperbilirubinemia receiving phototherapy for first time (As per AAP guideline) were included in the study.

- Infants under LED phototherapy were kept naked except for eyes and genitalia. Neonate was taken out only for feeding.

- Serum bilirubin estimation was done 12 hourly and relevant investigations done.

- Phototherapy was stopped when one value of serum bilirubin level reached below cut-off line according to AAP guideline.

- Serum bilirubin levels were measured at 12 hours and 24 hours after discontinuation of phototherapy to see rebound hyperbilirubinemia.

- Out of 150 neonates, $83(55.3 \%)$ were near term and $67(44.7 \%)$ were term neonates. Mean gestational age of neonates was $36.96 \pm 1.71$ weeks. There were 87 neonates $(58 \%)$ were male and 63 neonates $(42 \%)$ were female.

- Out of 150 neonates, in 86 neonates $(57.3 \%)$ no rebound hyperbilirubinemia, 47 neonates $(31.3 \%)$ developed insignificant rebound hyperbilirubinemia (i.e. serum bilirubin level increases after discontinuation of phototherapy but not crossed cut-off value of starting phototherapy), 10 neonates $(6.7 \%)$ developed SBR at $12 \mathrm{hrs}$. of discontinuation of phototherapy, and 7 neonates (4.7\%) developed SBR at $24 \mathrm{hrs}$. of discontinuation of phototherapy. Total 17 neonates (11.3\%) developed SBR.

- Percentage of rebound hyperbilirubinemia was more in near term neonates $(14.5 \%)$ as compared to term neonates $(7.5 \%)$. This difference was however found to be statistically non-significant $(\mathrm{P}=0.278)$.

- Significant association was seen between rebound hyperbilirubinemia and Sepsis $(\mathrm{p}=0.004)$, G6PD deficiency $(\mathrm{p}=0.001), \mathrm{Rh}$ incompatibility $(\mathrm{P}=0.026)$ and positive DCT $(\mathrm{p}=0.005)$. Rebound hyperbilirubinemia was also more in neonates with ABO incompatibility $(\mathrm{P}=0.113)$, cephalhematoma $(\mathrm{P}=0.802)$, perinatal asphyxia $(\mathrm{P}=0.859)$ and hypothyroidism $(\mathrm{P}=0.923)$ however value is statistically non-significant.

- In our study no statistically significant association was found between SBR and gender of neonate $(\mathrm{P}=0.851)$; SBR and age at onset of phototherapy $(\mathrm{P}=0.493)$; $\mathrm{SBR}$ and duration of phototherapy $(\mathrm{P}=0.940) ; \mathrm{SBR}$ and birth weight $(\mathrm{P}=0.797)$.

- In our study mean serum bilirubin at discontinuation of phototherapy in patients with significant rebound hyperbilirubinemia was higher $16 \mathrm{mg} / \mathrm{dl}$ at 12 hours and $17.9 \mathrm{mg} / \mathrm{dl}$ at 24 hours as compared to those with no or insignificant rebound hyperbilirubinemia in which mean serum bilirubin was $12.6 \mathrm{mg} / \mathrm{dl}$ at 12 hours and $13 \mathrm{mg} / \mathrm{dl}$ at 24 hours respectively and this difference was found to be statistically significant $(\mathrm{p}<0.001)$. So patient having higher serum bilirubin at the time of discontinuation of phototherapy along with risk factors developed more SBR.

\section{Conclusion}

Our study recommends repeat serum bilirubin testing at 12 hours or 24 hours after discontinuation of phototherapy to check rebound increase of hyperbilirubinemia. Significant association of rebound hyperbilirubinemia was seen with sepsis $(\mathrm{p}=0.004)$, G6PD deficiency $(\mathrm{p}=0.001), \quad \mathrm{Rh}$ incompatibility $(\mathrm{P}=0.026)$ and DCT positivity $(\mathrm{p}=0.005)$.

\section{REFERENCES}

1. Namasivayam A, Waldemar A. Carlo: Nelson Textbook of Pediatrics - 20e [UnitedVRG]-1 102.3 Jaundice and Hyperbilirubinemia in the Newborn. 2015; 871-879.

2. Burke B, Robbins J, Hobbs C. American Academy of Pediatrics Subcommittee on Hyperbilirubinemia Management of hyperbilirubinemia in the newborn infant 35 or more weeks of gestation. Pediatrics. 2004;114(1):297-316.

3. Mary Lucia PG, Camilia RM, John PC. Cloherty manual of neonatal care 7 th edition : Neonatal Hyperbilirubinemia. 304-339

4. Kramer LI. Advancement of dermal icterus in the jaundiced newborn. Am J Dis Child. 1969; 118:454-458

5. Anuradha B, Suksham J, Veena P, Deepak C, Bilirubin R. After Intensive Phototherapy for Neonatal Jaundice. From the Department of Pediatrics, Government Medical College Hospital, Chandigarh, India.

6. Niknafs N, Nili F, Dalili H, Nayeri F, Esmaeilnia T, Amini E. A Comparison of Significant Bilirubin Rebound after Discontinuation of Phototherapy in Two Groups of Neonates in Valiasr Hospital: A Randomized Clinical Trial. Iranian Journal of Neonatology IJN. 2014;4(4):17-21.

7. Maisels MJ, Kring E. Rebound in serum bilirubin level following intensive phototherapy. Archives of pediatrics \& adolescent medicine. $2002 \mathrm{Jul}$ 1;156(7):669-72.

8. Chang PW, Kuzniewicz MW, McCulloch CE, Newman TB. A clinical prediction rule for rebound hyperbilirubinemia following inpatient phototherapy. Pediatrics. 2017 Mar 1;139(3):e20162896.

9. Valinjkar SK, Sutay NR, Sharma B. Rebound hyperbilirubinemia in neonates after phototherapy and factors affecting it. JMSCR. 2017;5:19003-4. 
10. Diamond I. Kernicterus: revised concepts of pathogenesis and management. Pediatrics. 1966 Oct 1;38(4):539-42.

11. Arakhita S, Shantisena M, Ajit M, Saiprasanna B. A Study of Rebound Hyperbilirubinemia in Post Phototherapy Neonates.

12. Soni R, Kaushik SL, Kaushik R, Bhardwaj P, Mohabey S. Post phototherapy bilirubin rebound: incidence and risk factors. Int J Res Med Sci. 2017 Aug 26;5(9):4112.

13. Elhawary IM, Ghany EA, Aboelhamed WA, Ibrahim SG. Incidence and risk factors of postphototherapy neonatal rebound hyperbilirubinemia. World Journal of Pediatrics. 2018 Aug 1;14(4):350-6.

14. Kaplan M, Kaplan E, Hammerman C, Algur N, Bromiker R, Schimmel MS, Eidelman AI. Post- phototherapy neonatal bilirubin rebound: a potential cause of significant hyperbilirubinaemia. Archives of disease in childhood. 2006 Jan 1;91(1):31-4.

15. Praveen K, Lins P, Venkataseshan S. PostPhototherapy Bilirubin Rebound in Late Preterm and Term Neonates: A Prospective Observational Study.

16. Al-Saedi SA. Rebound hyperbilirubinemia in term infants after phototherapy. Saudi medical journal. 2002 Nov 1;23(11):1394-7.

17. Berkwitt A, Osborn R, Grossman M. The utility of inpatient rebound bilirubin levels in infants readmitted after birth hospitalization for hyperbilirubinemia. Hospital pediatrics. 2015 Feb 1;5(2):74-8. 